\title{
Temporal and spatial distribution of lumpy skin disease outbreaks in Ethiopia in the period 2000 to 2015
}

\author{
W. Molla $a^{1,2^{*}}$ (D, M. C. M. de Jong ${ }^{1}$ and K. Frankena ${ }^{1}$
}

\begin{abstract}
Background: Lumpy skin disease (LSD) is an infectious viral disease of cattle caused by a virus of the genus Capripoxvirus. LSD was reported for the first time in Ethiopia in 1981 and subsequently became endemic. This time series study was undertaken with the aims of identifying the spatial and temporal distribution of LSD outbreaks and to forecast the future pattern of LSD outbreaks in Ethiopia.

Results: A total of 3811 LSD outbreaks were reported in Ethiopia between 2000 and 2015. In this period, LSD was reported at least once in $82 \%$ of the districts $(n=683), 88 \%$ of the administrative zones $(n=77)$, and all of the regional states or city administrations ( $n=9$ and $n=2$ ) in the country. The average incidence of LSD outbreaks at district level was 5.58 per 16 years $\left(0.35\right.$ year $\left.^{-1}\right)$. The incidence differed between areas, being the lowest in hot dry lowlands and highest in warm moist highland. The occurrence of LSD outbreaks was found to be seasonal. LSD outbreaks generally have a peak in October and a low in May. The trend of LSD outbreaks indicates a slight, but statistically significant increase over the study period. The monthly precipitation pattern is the reverse of LSD outbreak pattern and they are negatively but non-significantly correlated at lag 0 ( $r=-0.05, p=0.49$, Spearman rank correlation) but the correlation becomes positive and significant when the series are lagged by 1 to 6 months, being the highest at lag $3(r=0.55, p<0.001)$. The forecast for the period 2016-2018 revealed that the highest number of LSD outbreaks will occur in October for all the 3 years and the lowest in April for the year 2016 and in May for 2017 and 2018.
\end{abstract}

Conclusion: LSD occurred in all major parts of the country. Outbreaks were high at the end of the long rainy season. Understanding temporal and spatial patterns of LSD and forecasting future occurrences are useful for indicating periods when particular attention should be paid to prevent and control the disease.

Keywords: Ethiopia, Lumpy skin disease, Time series, Spatial, Temporal, Forecast

\section{Background}

Lumpy skin disease (LSD) is an infectious viral disease of cattle caused by LSD virus of the genus Capripoxvirus and the disease often occurs as epidemics. It has spread from Zambia, where it was first observed in 1929 to most African countries (except Libya, Morocco, Algeria and Tunisia), Middle Eastern countries, and more recently also to European countries [1-5]. LSD can occur in diverse ecological zones from the very dry semi-desert, the wet and dry areas to the high altitude temperate areas [1].

\footnotetext{
* Correspondence: wassie.abebe@wur.nl; mollawassie@yahoo.com ${ }^{1}$ Quantitative Veterinary Epidemiology, Wageningen University \& Research, Droevendaalsesteeg 1, 6708 PB Wageningen, The Netherlands

${ }^{2}$ Faculty of Veterinary Medicine, University of Gondar, P.O. Box 196, Gondar, Ethiopia
}

(c) The Author(s). 2017 Open Access This article is distributed under the terms of the Creative Commons Attribution 4.0 International License (http://creativecommons.org/licenses/by/4.0/), which permits unrestricted use, distribution, and reproduction in any medium, provided you give appropriate credit to the original author(s) and the source, provide a link to the Creative Commons license, and indicate if changes were made. The Creative Commons Public Domain Dedication waiver (http://creativecommons.org/publicdomain/zero/1.0/) applies to the data made available in this article, unless otherwise stated. through north-west (Gojjam and Gondar) in 1981 with subsequent introductions in the West (Wollega) in 1982 from Sudan and in the central part (Shewa) in 1983 [6]. After the introduction, the disease initially spread Eastwards, later to all directions and currently it has affected all regions and agro-climatic zones of the country [6-8]. The spread of LSD was enhanced by uncontrolled cattle movements, communal grazing and watering, and pastoralism [2, 7]. The poor animal health situation, inefficient prevention and control efforts in combination with late detection of the disease have further contributed to the spread of LSD in Ethiopia [2, 8].

In general, the temporal pattern of disease occurrence can be described with short-term, cyclical and seasonal, 
and long-term trends; time series analysis is a frequently used method to assess these temporal patterns [9]. The cyclical trends are associated with regular, periodic fluctuations in the level of disease occurrence. A seasonal trend is a special case of a cyclical trend, where the periodic fluctuations in disease incidence are related to particular seasons [9]. Seasonal variation in the occurrence of infectious diseases is a common phenomenon in both temperate and tropical climates. Seasonal changes in vector abundance are well-known causes of seasonality of vector-borne infections. A good knowledge on the seasonal variation of disease outbreaks has paramount importance for the understanding of the dynamics of the disease and in designing better control strategies [10].

Field observations and experimental studies indicate that blood feeding arthropods are involved as passive vectors in the transmission of LSD virus [2, 11]. The spread of LSD has been frequently associated with epidemics [12]. Epidemics of LSD occurred during the rainy season in which the arthropod vector populations are abundant while LSD incidence sharply drops during the dry and cold weather seasons $[1,13,14]$. Seasonal variation in the incidence of LSD outbreaks is common in Ethiopia in which it occurs most frequently between September and December [15]. Resurgence of the disease has been consistently associated with the high rainfall, emergence of large numbers of vectors and a low level of herd immunity $[13,16]$. Epidemics of LSD were reported to recur at intervals of 5 or 6 years [13]. The reoccurrence of the disease in provisionally free area is possible when the infection is introduced into the population and the reproduction ratio $(\mathrm{R})$, the average number of secondary cases caused by a single typical infectious individual, becomes greater than one [17].

Animal disease monitoring data is of fundamental importance to know the disease status of a country. In Ethiopia, the disease monitoring is mainly passive as most of the disease outbreaks reported to the federal veterinary services are based on clinical observations [18]. Monitoring of livestock diseases in the field is the responsibility of regional animal health services, regional veterinary laboratories and district animal health personnel. Disease investigations are generally conducted in response to reports of health problems from livestock owners. There is a regular follow up of disease outbreaks but the monthly livestock disease reporting rate is less than $47 \%$ which is below the required OIE (world organization for animal health) standards of at least 80\% [19].

Assessing the spatial and temporal patterns is a prerequisite for guiding successful surveillance and control efforts in a country. Therefore, the objectives of this study were to evaluate the spatial and temporal distribution of LSD outbreaks and to forecast future patterns of outbreaks in Ethiopia based on data reported over the period 2000-2015.

\section{Methods}

Study area

Ethiopia is located in Eastern Africa bordering with Sudan, Eritrea, Djibouti, Somalia, Kenya, and South Sudan. It is a federation of nine member regional states (Tigray, Afar, Amhara, Oromia, Benshangul-Gumuz, Gambella, Southern Nations Nationalities and Peoples Region (SNNP), Harari, and Somali) and two city administrations (Addis Ababa and Dire Dawa). The regional states and city administrations are further divided into zones and the zones into woredas (districts), and the woredas into kebeles. As a whole there are about 15,000 kebeles (5000 urban dwellers associations in towns and 10,000 peasant associations in rural areas) in the country [20-22]. The country's territory presents a diverse topography, ranging from $116 \mathrm{~m}$ below sea level at the Dallol Depression, in the East, to $4620 \mathrm{~m}$ above sea level on the Ras Dashen in the North and covers an area of approximately 1.1 million $\mathrm{km}^{2}$. Ethiopia is broadly divided into three climatic zones: "Kolla" (the hot lowland zone below $1500 \mathrm{~m}$ ); "Weyna Dega" (mid highland zone between 1500 and $2400 \mathrm{~m}$ ); and "Dega" (the cool highlands zone above $2400 \mathrm{~m}$ ). Average daily temperature ranges from $20{ }^{\circ} \mathrm{C}$ to $30{ }^{\circ} \mathrm{C}$. Rainfall ranges from 200 $\mathrm{mm}$ to $2000 \mathrm{~mm}$ per year. Ethiopia receives heavy rainfall in June, July and August and occasional showers in February and March. In general, the highlands of Ethiopia receive more rain than the lowlands $[20,21]$.

The total cattle population of the country is estimated to be about 56.71 million heads, mostly local breeds (98.7\%); the remaining are hybrid (1.2\%) and exotic breeds (0.1\%) [23]. The livestock production system practiced in the country is usually extensive. In the highland and mid highland, it is highly integrated with crop production where cattle are primarily kept for traction purpose and to provide milk and meat as by-products. In the lowland, where no or little farming is practiced, pastoralists and agro-pastoralists keep cattle to provide mainly milk $[23,24]$.

\section{Outbreak and weather data}

LSD is a notifiable disease and it is required that all occurrences of this disease be reported. LSD outbreak data were obtained from the Federal Veterinary Services Directorate of Ethiopia for the period 2000-2015. The records contained information on place, time, number of cases, number of deaths and number of animals at risk for each month. The reporting format enables calculation of the temporal and spatial distribution of LSD. An outbreak is defined as one or more bovines showing LSD symptoms in a specified geographical area (usually Kebele). During the 16 years period, no significant changes in operation of the veterinary organization that could have affected the level of reporting from the field were noted. 
The LSD outbreak incidence was established at district (woredas, $n=683$ ) level using the 16 years outbreak data. The mean LSD outbreak incidence in a district was calculated by summing all reported LSD outbreaks in a district over the study period and divide it by 16 . The geographical distribution of LSD outbreaks over the 16 years was mapped by administrative zone using GIS software QGIS 2.2 (QGIS developer team, Open Source Geospatial Foundation, 2014). The spread of the epidemic was also shown using SPMAP (South Platte Mapping and Analysis Program, Stata 14) by superimposing the yearly outbreak data onto Ethiopian Woreda 2008 shape files in Microsoft power point program.

The monthly mean precipitations for the period 19992013 were obtained from the Global weather data for SWAT (Soil, Water, and Air Team) website. From a meteorological point of view, three seasons can be distinguished in Ethiopia; 'Belg' (February to May), 'Kiremt' (June to September) and 'Bega' (October to January). 'Kiremt' is the main rainy season in which the magnitude of rainfall is highest as compared to the other seasons for many parts of the country [25].

\section{Data analysis}

Data on the number of LSD outbreaks reported each month during the 16-year study period were analysed to detect temporal trends and seasonal effects. A simple inspection of the graph of the original LSD outbreak time series was employed to appreciate the presence of a clear long-term trend or seasonal effect. The existence of a long-term trend in LSD outbreaks was modelled by linear regression (STATA version 14) using the number of LSD outbreaks (or trend component of the outbreak) as dependent variable and month of the outbreaks as explanatory variable. Spectral analysis with SAS (Statistical Analysis Software) 9.4 was performed to detect seasonality and cyclical patterns in the LSD outbreak time series.

Decomposition of LSD outbreak time series was performed using package 'TTR' (Technical Trading Rules) in $\mathrm{R}$ software, to identify and estimate the three components of the temporal additive model: seasonality, longterm trend, and irregularity [26].

The time series were also seasonally differenced (i.e. deducting the 12 months earlier observation value from each observation value) first followed by first order trend differencing (i.e. deducting the preceding observation value from each observation value) according to the procedure described by Allard [27] and Coghlan [26] to make the series stationary (diff function in R). Next autocorrelation analysis (Autocorrelation function in $\mathrm{R}$ ) was used to assess the seasonality of the differenced time series. The autocorrelation function (ACF) enables to test the significance of seasonality in a time series by examining the ACF correlogram at lags of 12 month intervals [28]. The ACF estimates the correlation between the number of outbreaks reported in a given month and the number of outbreaks reported in each of the previous 1 to 192 months. The autocorrelations and partial autocorrelations values of various lags were used for the selection of terms to be included in the initial autoregressive integrated moving average (ARIMA) model (autocorrelations and partial autocorrelations functions in R).

The Holt-Winters exponential smoothing technique as described by Coghlan [26] was applied to make short term (36 months) forecasts using package 'forecast' in $\mathrm{R}$ software. The possibility of improving the predictive model was evaluated by making a correlogram and carrying out the Ljung-Box test on the in-sample forecast errors for evidence of non-zero autocorrelations at lags 1 to 20 . In this method the estimates of the parameters alpha, beta, and gamma represents the level, the slope of the trend component, and the seasonal component, respectively at the current time point. All the three parameters have values between 0 and 1 . Parameter values that are close to 0 indicate that relatively little weight is placed on the most recent observations while forecasting future values.

Exponential smoothing methods are useful for making forecasts, but it does not take into account the correlations between successive values of the time series. However, a better predictive model can be made by taking correlations in the data into account. ARIMA models include an explicit statistical model for the irregular component of a time series that allows for non-zero autocorrelations in the irregular component. An ARIMA $(1,1,1)$ x $(1,1,1) 12$ model [26, 29] seemed a plausible model for the LSD outbreak stationary time series and this model was used to forecast the expected numbers of LSD outbreaks for a 36 month (January 2016 to December 2018) future time using the "forecast.Arima()" function in the "forecast" $\mathrm{R}$ package. Finally, it was investigated whether or not successive forecast errors of an ARIMA $(1,1,1) \times(1,1,1) 12$ models were correlated by making a correlogram and carrying out the Ljung-Box test.

The association between monthly rainfall and monthly LSD outbreaks was tested with Spearman rank test (Stata version 14).

\section{Results}

Geographical distribution and incidence of LSD outbreaks During the period 2000-2015, LSD has been reported from all regional states $(n=9)$ and city administrations $(n=2)$ of Ethiopia. About $82 \%$ of the districts $(n=683)$ and $88 \%$ of the administrative zones $(n=77)$ in the country reported at least one LSD outbreak in this time period. In total 3811 LSD outbreaks were reported in Ethiopia during the study period (Additional file 1: Table S1). Most of these outbreaks were from Oromia (54.5\%), Amhara (27.9\%), SNNP (10.1\%) and Tigray regional states (3.6\%) (Additional file 2: Figure S1). 
The average incidence of LSD outbreaks at district level was 5.58 over all 16 years or 0.35 per district per year. The lowest incidences were observed in the eastern lowland (Afar and Somali), southern lowland (Liben), south-west (Benchi Maji) and North (North western zone of Tigray) areas whereas the highest number of outbreaks were documented in the north-west, central, West and south-western parts of the country (Fig. 1).

The data shows that LSD affects districts for one or two years and then spreads to other nearby districts/ areas with a susceptible cattle population. In this fashion the disease moves from one geographical area to the other and circulates in the country (Additional file 3: Figure S2). The reoccurrence of the disease in the study districts varies from 1 year to 13 years, with average length of 4.54 years and median 4 years. The time between outbreaks was shorter in districts geographically located in the West, south-west and central part of the country.

\section{LSD outbreak time series description and analysis}

The monthly distribution of LSD outbreaks is presented in Fig. 2, Additional file 1: Table S1 and Additional file 4: Figure S3. It showed a slight increase in the number of monthly outbreaks which was statistically significant $(P<0.05)$ (Fig. 2). The seasonality in the numbers of outbreaks is apparent, which tend to be higher in the months following the long rainy season compared to other seasons (Fig. 2). The undecomposed and undifferenced original LSD outbreak time series was found seasonal by spectral analysis techniques (Fig. 3).

The trend, seasonal and irregular components of the LSD outbreak time series were estimated by decomposing the time series (Fig. 4). The estimated trend component shows a decrease from about 20 outbreaks in 2002 to about 6 outbreaks in 2006, followed by a substantial increase to about 41 outbreaks in 2009, decrease to about 16 outbreaks at the end of 2013 and finally increase to about 26 outbreaks in 2014. Though the LSD outbreak pattern from the trend component appears to have a cycle with a periodicity of 5-7 years (peaks in 2002, 2009 and 2014) (Fig. 4) it was not established by spectral analysis. Linear regression on the trend component of the decomposed time series shows a statistically significant $(p<0.001)$ increase in monthly LSD outbreak numbers between 2000 and 2015.

The seasonal pattern of LSD outbreaks is clearly indicated in Figs. 3 and 4. Seasonal factors were estimated for each month over the 16 year period as the seasonal component of the decomposed LSD time series. The largest seasonal factor is recorded for October (about 16.8) and the lowest for May (about -12.1), indicating that number of LSD outbreaks peaks in October and has a low (trough) in May (Figs. 4 and 5). In general the number of LSD outbreaks was above average for the months September to January and below average for February to August (Fig. 5).

The rainfall season of Ethiopia is indicated in Figs. 2 and 5. The precipitation is above average from April to September and below average from October to March. The rainfall is high in July and August and low in December to February. The precipitation pattern is the reverse of LSD outbreak pattern (Fig. 5), resulting in a negative correlation coefficient $(r=-0.05, p=0.49$, Spearman rank correlation) at lag 0 and positive correlation coefficients when the series were lagged by 1 to 6 months, the correlation at lag 3 being the highest $(r=$ $0.55, p<0.001)$.

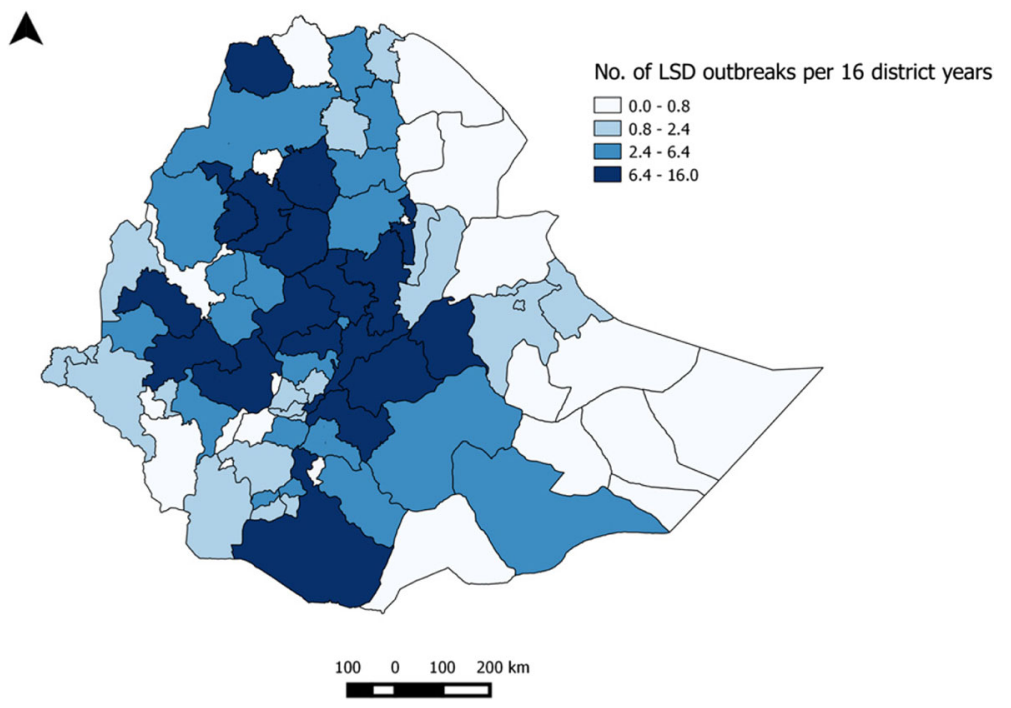

Fig. 1 Zonal distribution of LSD outbreaks per 16 district years in Ethiopia over the period 2000-2015 


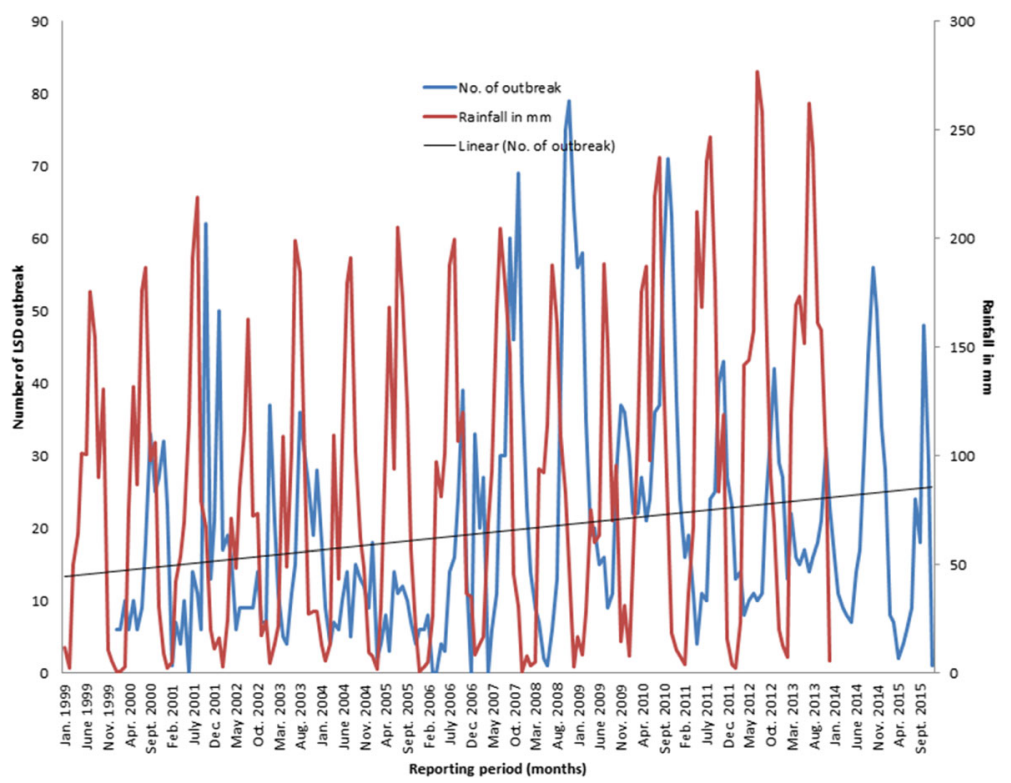

Fig. 2 Monthly outbreak and trend of LSD from 2000 to 2015 and monthly rainfall in millimetre from 1999 to 2013 in Ethiopia

\section{LSD outbreak times series forecasting}

For forecasting with Holt-Winters exponential smoothing, the three parameters: alpha, beta, and gamma which are important for forecasting future values were 0.56, 0.00 , and 0.32 , respectively. The original LSD outbreak times series and the forecasted values plotted using Holt's exponential smoothing is shown in Additional file 5: Figure S4. The future times, from January 2016 to December 2018 were also forecasted with Holt-Winters' exponential methods (Additional file 6: Figure S5). However, the correlogram and Ljung-Box test showed the presence of significant $(P=0.002)$ autocorrelations of the in-sample forecast errors at lags 1-20. This indicates that Holt-Winters exponential smoothing could not provide an adequate forecast.

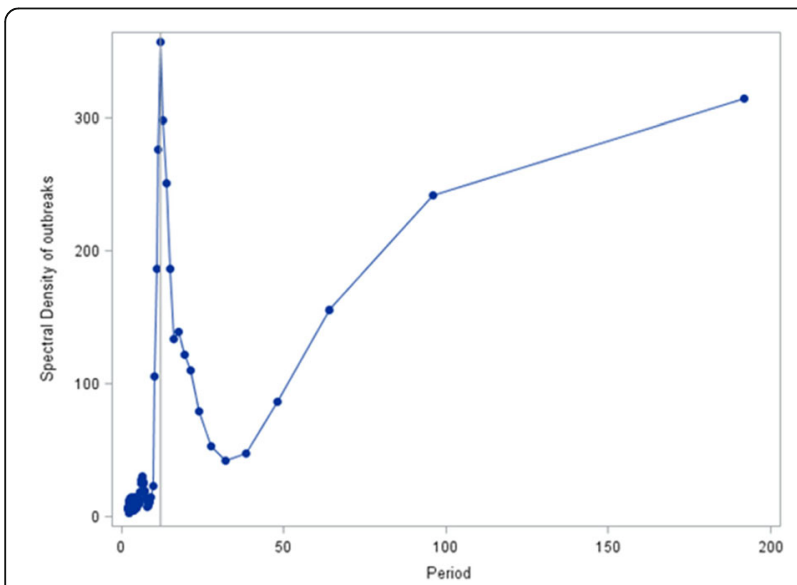

Fig. 3 Spectral density estimates of LSD outbreaks by month, the vertical reference line at the 12 month period shows the seasonality of the disease
The LSD outbreak time series was differenced for trend and seasonality, and the resulting series of first order differences appeared to be stationary in mean and variance. The ACF correlogram of first differenced LSD time series indicates significant autocorrelation at lag 1 (-0.349), 12 (-0.468), and 13 (0.273) (Additional file 7: Figure S6A). This demonstrates the seasonality of the series because the current monthly value is related to the value of 12 months earlier. The partial correlogram also shows that the partial autocorrelations at lags 1 (-0.349), 9 (-0.199), $12(-0.487)$ and $15(0.185)$ exceed the significance bounds (Additional file 7: Figure S6B). Hence, the ARIMA model $(1,1,1) \mathrm{x}(1,1,1) 12$ was used for making forecasts for the number of LSD outbreaks from January 2016 to December 2018 (Fig. 6). The correlogram for the forecasted value shows that none of the sample autocorrelations for lags 1-20 exceed the significance bounds, and the $p$-value for the Ljung-Box test is 0.107 , so it can be concluded that there is little evidence for non-zero autocorrelations in the forecast errors at lags 1-20. Based on the forecast, the highest numbers of LSD outbreaks are expected in October for all predicted years and the lowest in April for 2016 and May for 2017 and 2018 (Additional file 8: Table S2).

\section{Discussion}

In the current study, LSD has been recorded from all regional states and city administrations in Ethiopia. A previous retrospective study that covered a period from January 2007 to December 2011 reported no outbreaks from Dire Dawa city administration and Harari regional state [15]. The present study, however, showed that they are affected by the disease. 


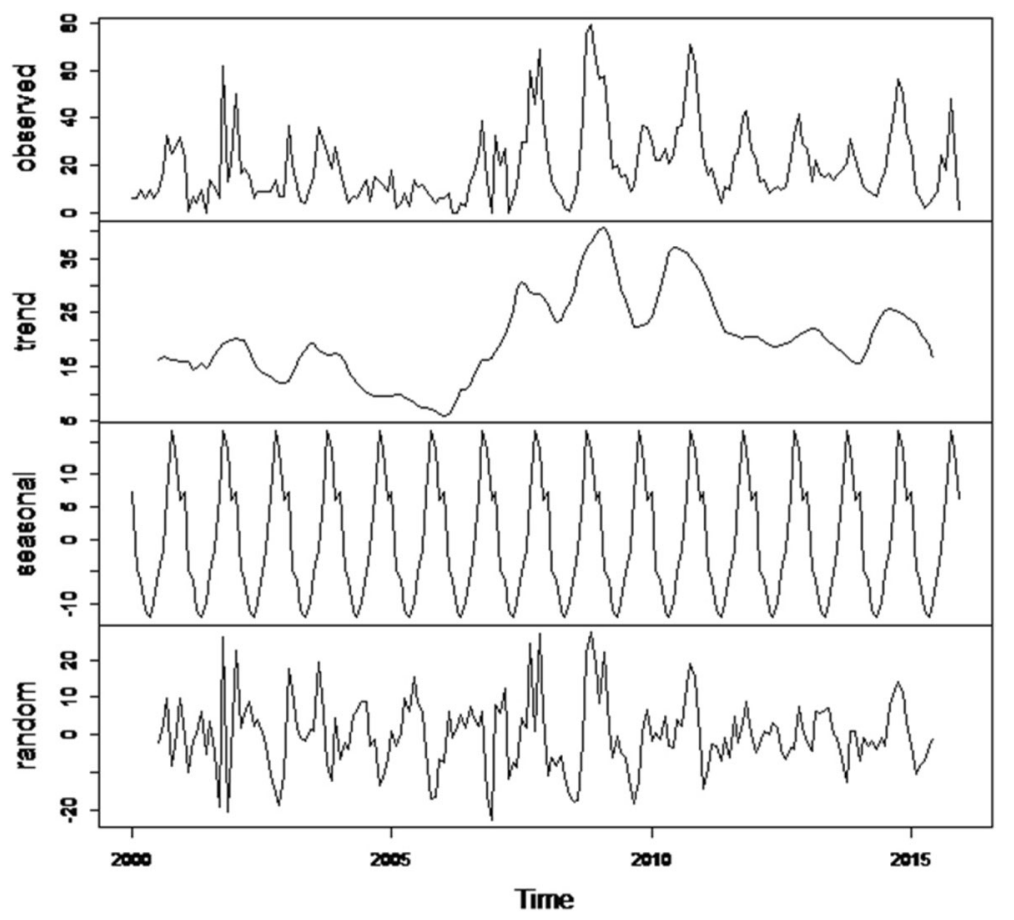

Fig. 4 Decomposition of the time series of the number of LSD outbreaks (top panel) into three components: trend, seasonality and random

Our spatial analysis have shown that distribution of incidence of LSD outbreaks vary among areas (Fig. 1). The highest LSD incidences were in warm moist highland and the lowest in hot dry lowland areas. This indicate that the parts of the country which receive relatively high rain fall for a reasonable period of time is conducive for the replication and survival of blood feeding arthropods and then for the spread of the disease in the geographical areas $[7,15,30,31]$. The LSD outbreak incidence indicated for the different zones should be treated consciously because under reporting might result in an underestimated incidence.

In this study, it became clear that the occurrence of LSD in an area/districts is sporadic. However, endemicity of the disease is maintained in the country because the outbreaks in different districts/area do not occur at the same time (Additional file 3: Figure S2). The average time to reoccurrence was 4.54 years, in line with the 5 yearly reoccurrence of LSD epidemic in unvaccinated populations [31]. The reoccurrence was variable across the study districts. Some districts reported outbreaks after 1 year of quiescence, whereas others reported an outbreak after a much longer period (up to 13 years), which is in line with Gari et al. [7]. This indicates that the disease is not endemic in a district/an area but it occurs in an outbreak (epidemic) form after some years. The reoccurrence is only possible after the seroprevalence (herd immunity) dropped below the critical value and reproduction ratio

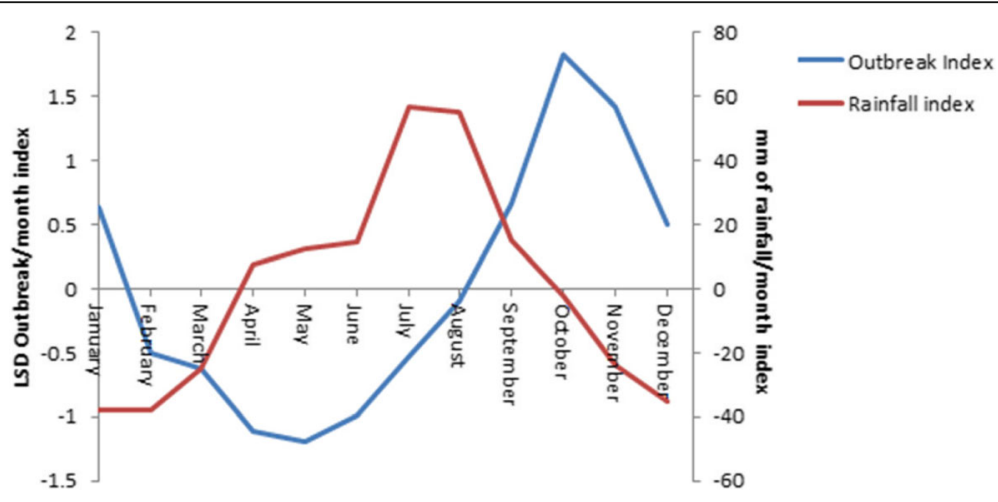

Fig. 5 Seasonal indices of monthly LSD outbreak between 2000 and 2015 and mean rainfall between 1999 and 2013 in Ethiopia 


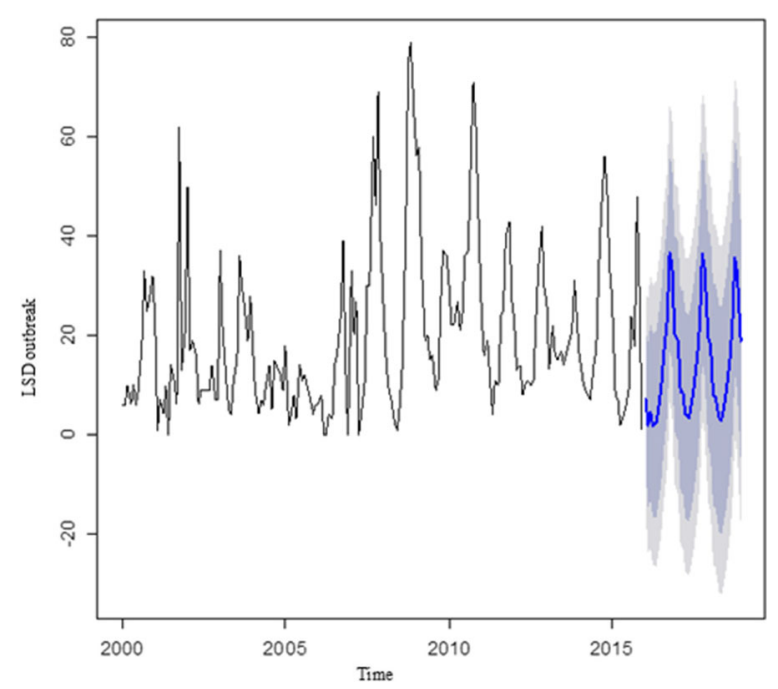

Fig. 6 The original LSD outbreak time series (2000-2015) and predicted for the next three years (2016-2018) using ARIMA $(1,1,1) \times$ $(1,1,1) 12$ model. The black line represents the original LSD outbreak time series and the blue line the forecasted value. The dark grey shaded area indicate the $80 \%$ confidence interval and the light grey 95\% confidence interval of the predicted values

(R) is above one. How long it will take depends on the rate at which LSD is introduced into the district/area (spark rate) and how far the $R$ has increased above one [17]. The time between outbreaks was shorter in the West and south-west (where rainfall occurs for extended periods of time) and central (where live animal from different parts of the country cross through to the central market) parts of the country.

LSD outbreaks do also not occur at random in time and we demonstrated the seasonality by spectral analysis (Fig. 3) and estimated a significant autocorrelation between LSD outbreaks at lag 12, 24, 36, etc., indicating the seasonality of the disease. The seasonal pattern of the disease is also clearly indicated in Fig. 4. The seasonal LSD outbreak variation might be related to the variation in temperature and rainfall between seasons leading to varying arthropod densities in the environment. Seasonal variations in vector abundance, including mosquitoes, ticks, and flies, are well known causes of seasonality for vector borne diseases [10]. Identification of temporal patterns can indicate times when particular attention should be paid to control the disease [9].

The trend of LSD outbreaks from January 2000 to December 2015 indicates a slight, but statistically significant increase over the period (Figs. 2 and 4). This might be attributed to the absence of a specific national strategy for LSD control or eradication [18] and the increased tendency of using irrigation for crop cultivation that create favourable environmental conditions for vector borne diseases in the country. The implication of the trend component is that the disease will continue to persist if the environmental circumstances and the poor disease control activities continue.

The positive and significant cross correlations between precipitation and increased LSD outbreaks at lag 3 ( $r=$ $0.55, p<0.001)$ suggests that the rainfall in the previous months are an important factor for the occurrence of LSD outbreaks. The time delay for LSD outbreaks to occur might be justified by the time required for the build-up of arthropod population following the rains $[32,33]$, incubation period (2-4 weeks [34]) of the virus within the cattle host and delay in reporting.

Based on the 2000-2015 reports, the number of LSD outbreaks to occur in each month from 2016 to 2018 was forecasted. The forecast suggests that high number of LSD outbreak will occur from August to January and this is comparable with the available LSD outbreak time series data. The reappearance of the seasonality in the original time series again in the forecasts is an indication of the forecast is reasonable [27]. The wide confidence interval (Fig. 6) indicates the need of frequent updating of the model by incorporating the latest outbreak reports [27]. The confidence interval was even wider when HoltWinters' exponential methods were used (Additional file 6: Figure S5). The wider confidence interval is related to a limitation of this method, i.e. it does not take the correlations between successive values of the time series into account. The ARIMA model, taking the correlations in the data into account, therefore, is the preferred model to get a reasonable forecast in this study [26]. The forecasting process can be continued to any point in the future, but will become less reliable for predictions further in time [29]. This means we can only gain advantage from the use of short term forecasts. The forecasted results of this study, therefore, will alert and help policy makers to focus on the unusual situations to decide whether any disease control intervention is required to halt the occurrence of the disease in the future.

Currently, Ethiopia has no a well-designed control strategy for LSD [18]. The animal health authority undertake reactive vaccination campaign using Kenyan sheep pox vaccine when an LSD outbreak is reported somewhere in the country. Vaccination is the only measure taken for LSD control. However, research findings indicate that the vaccine used in Ethiopia is not fully protective [35] which might be the reason for the increase in incidence of LSD outbreaks observed over the current study period. Because there is no regular vaccination program against LSD this might attribute to a drop of herd immunity below the critical point and for the reoccurrence of the disease. We now understood that LSD does not establish endemicity in an area, but it recurs as epidemic in, at average, every 5 years. Therefore, outbreaks might be prevented by bringing the herd 
immunity above the critical level through vaccination and by prohibiting the entrance of infected animals to the provisionally free area. Vaccination should be undertaken regularly ahead of the onset of the main rainy season with a high coverage. The vaccine currently in use shall be replaced by more competent homologous (Neethling virus) vaccine [36]. It is widely agreed that vaccination is the most manageable and realistic approach to control the disease in endemic and resource poor countries. However, to be more effective, the vaccination should be complemented by other additional measures such as movement control.

\section{Conclusion}

LSD is wide spread and well established in Ethiopia. It occurred in all regional states and city administrations in the time period between 2000 and 2015. LSD does not establish endemicity in a district, but it does in the country as a whole. It recurs in a district as epidemic, on average in 5 years period. The average incidence of LSD outbreaks at district level was 5.58 over all 16 years. The trend of LSD outbreaks increased over time. Outbreaks are seasonal and occurred more often in the months following the long rainy season. The results of the spatiotemporal analysis and the forecasted value may serve as a guide for the routine surveillance of LSD in the country.

\section{Additional files}

Additional file 1: Table S1. Number of LSD outbreaks reported monthly over the period 2000-2015 in Ethiopia. (DOCX 17 kb)

Additional file 2: Figure S1. Distribution of LSD outbreaks $(n=3811)$ over regional states and city administrations in the period 2000-2015. (DOCX $14 \mathrm{~kb})$

Additional file 3: Figure S2. Animation of the spread of lumpy skin disease epidemics in Ethiopia, 2000-2015. (DOCX 2749 kb)

Additional file 4: Figure S3. Annual course of LSD outbreaks in Ethiopia, 2000-2015. (DOCX 169 kb)

Additional file 5: Figure S4. The original LSD outbreak time series (black) and the predicted values (red) using Holt-Winters filtering. (DOCX $27 \mathrm{~kb}$ )

Additional file 6: Figure S5. LSD outbreak forecasts based on HoltWinters analysis for January 2016 to December 2018. (DOCX 24 kb)

Additional file 7: Figure S6. ACF (A) and Partial ACF (B) correlogram after first order seasonal and trend differencing of the original LSD outbreak time series. (DOCX $21 \mathrm{~kb}$ )

Additional file 8: Table S2. 36 month forecast of the number of LSD outbreaks based on ARIMA $(1,1,1) \times(1,1,1) 12$. (DOCX $17 \mathrm{~kb})$

\section{Abbreviations}

ACF: Autocorrelation Function; ARIMA: Autoregressive Integrated Moving Average; LSD: Lumpy Skin Disease; OIE: Office International des Epizooties (world organization for animal health); R: Reproduction ratio; SAS: Statistical Analysis Software; SNNP: Southern Nations Nationalities and Peoples Region; SPMAP: South Platte Mapping and Analysis program; SWAT: Soil, Water, and Air Team; TTR: Technical Trading Rules

\section{Acknowledgements}

The authors are very much grateful to Nuffic for financing the study. We would like to acknowledge the Ethiopian Veterinary Services Directorate for allowing access to its LSD outbreak report records, and Dr. Bewket Sirawbezu, Dr. Getachew Gari and Dr. Yesmashewa Wogayehu for facilitating access to the database.

\section{Funding}

This work was financed by Nuffic (Netherlands organization for international cooperation in higher education). The funding organization has no role in the design of the study and collection, analysis, and interpretation of data and in writing the manuscript.

\section{Availability of data and material}

The datasets used and/or analysed during the current study are available from the corresponding author on reasonable request.

\section{Authors' contributions}

WM participated in the planning of the study, obtained the data, performed the analyses and drafted the manuscript. KF and MCMdJ participated in the planning of the study, analysed and interpreted the data, and revised the manuscript. All authors read and approved the final manuscript.

Ethics approval and consent to participate

Not applicable.

\section{Consent for publication}

Not applicable.

\section{Competing interests}

The authors declare that they have no competing interests.

\section{Publisher's Note}

Springer Nature remains neutral with regard to jurisdictional claims in published maps and institutional affiliations.

Received: 3 April 2017 Accepted: 30 October 2017

Published online: 06 November 2017

References

1. Davies FG. Lumpy skin disease, an African capripox virus disease of cattle. Br Vet J. 1991;147:489-503.

2. Tuppurainen ES, Oura CA. Review: lumpy skin disease: an emerging threat to Europe, the Middle East and Asia. Transbound Emerg Dis. 2012;59:40-8.

3. Tuppurainen ES, Venter EH, Shisler JL, Gari G, Mekonnen GA, Juleff N, Lyons NA, De Clercq K, Upton C, Bowden TR et al. Review: Capripoxvirus diseases: current status and opportunities for control. Transbound Emerg Dis. 2015; doi:101111/tbed12444

4. Tasioudi KE, Antoniou SE, lliadou P, Sachpatzidis A, Plevraki E, Agianniotaki El, Fouki C, Mangana-Vougiouka O, Chondrokouki E, Dile C. Emergence of lumpy skin disease in Greece, 2015. Transbound Emerg Dis. 2016:63:260-5.

5. WAHIS. Summary of immediate notifications and follow-ups. World animal health information database (WAHIS interface). 2016. http:/www.oie.int/wahis_2/public/ wahid.php/Diseaseinformation/Immsummary. Accessed 18 July 2016.

6. Mebratu GY, Kassa B, Fikre Y, Berhanu B. Observation on the outbreak of lumpy skin disease in Ethiopia. Rev Elev Méd Vét Pays Trop. 1984;37:395-9.

7. Gari G, Waret-Szkuta A, Grosbois V, Jacquiet P, Roger F. Risk factors associated with observed clinical lumpy skin disease in Ethiopia. Epidemiol Infect. 2010;138:1657-66.

8. APHRD. Ethiopia animal health yearbook 2011, Animal and plant health regulatory directorate (APHRD), Addis Ababa, Ethiopia. 2012.

9. Thrusfield M. Veterinary epidemiology. 3rd ed. Oxford, UK: Blackwell Science; 2007. p. 144-51.

10. Grassly NC, Fraser C. Seasonal infectious disease epidemiology. Proc R Soc B. 2006;273:2541-50

11. Chihota CM, Rennie LF, Kitching RP, Mellor PS. Mechanical transmission of lumpy skin disease virus by Aedes aegypti (Diptera: Culicidae). Epidemiol Infect. 2001;126:317-21.

12. Carn VM. Control of capripoxvirus infections. Vaccine. 1993:11:1275-9.

13. Woods JA. Lumpy skin disease- A review. Trop Anim HIth Prod. 1988;20:11-7.

14. Wainwright S, El Idrissi A, Mattioli R, Tibbo M, Njeumi F, Raizman E. Emergence of lumpy skin disease in the eastern mediterranean basin countries.FAO. 2013. http://www.fao.org/docrep/019/aq706e/aq706e.pdf. Accessed 20 August 2016. 
15. Ayelet G, Haftu R, Jemberie S, Belay A, Gelaye E, Sibhat B, Skjerve E, Asmare K. Lumpy skin disease in cattle in central Ethiopia: outbreak investigation and isolation and molecular detection of lumpy skin disease virus. Rev Sci Tech Off Int Epiz. 2014;33:877-87.

16. Hunter P, Wallace D. Lumpy skin disease in southern Africa: a review of the disease and aspects of control. J S Afr Vet Ass. 2001;72:68-71.

17. Dibble CJ, O'Dea EB, Park AW, Drake JM. Waiting time to infectious disease emergence. J R Soc Interface. 2016;13:20160540.

18. APHRD. Biannual epidemiology newsletter, animal and plant health regulatory directorate (APHRD), Ministry of Agriculture, Addis Ababa, Ethiopia. 2012

19. APHRD. Ethiopia animal health yearbook (2009/10), animal and plant health regulatory directorate (APHRD), Ministry of Agriculture, Addis Ababa, Ethiopia. 2010.

20. Tadesse D, Desta A, Geyid A, Girma W, Fisseha S, Schmoll O. Rapid assessment of drinking water quality in the Federal Democratic Republic of Ethiopia: country report of the pilot project implementation in 2004-2005. World Health Organization (WHO) and UNICEF. 2010; http://www.wssinfo.org/ fileadmin/user_upload/resources/RADWQ_Ethiopia.pdf. Accessed 9 July 2016

21. GoE. Ethiopian government portal: official web gateway to the government of Ethiopia (GoE). 2016. http://www.ethiopia.gov.et. Accessed 8 November, 2016.

22. Mbogo CM. Current status of entomological monitoring and surveillance for an effective delivery of vector control interventions in Ethiopia. Produced for review by the United States Agency for International Development 2012. http://pdf.usaid.gov/pdf_docs/PA00J33M.pdf. Accessed 9 July 2016.

23. CSA: Agricultural sample survey, 2014/15 (2007 E.C.), volume II: report on livestock and livestock characteristics (private peasant holdings). Statistical bulletin 578. Central statistical agency (CSA), Federal Democratic Republic of Ethiopia, Addis Ababa. 2015.

24. Gari G, Grosbois V, Waret-Szkuta A, Babiuk S, Jacquiet P, Roger F. Lumpy skin disease in Ethiopia: seroprevalence study across different agro-climate zones. Acta Trop. 2012;123:101-6.

25. NMA. Annual climate bulletin, national meteorological agency (NMA), Addis Ababa Ethiopia. 2013. http://www.ethiomet.gov.et/bulletins/view_pdf/348/ 2013 annual bulletin.pdf. Accessed 30 June, 2016.

26. Coghlan A. A little book of $R$ for time series, Release 0.2. 2015. https:// media.readthedocs.org/pdf/a-little-book-of-r-for-timeseries/latest/a-littlebook-of-r-for-time-series.pdf. Accessed 18 May 2016.

27. Allard R. Use of time-series analysis in infectious disease surveillance. Bull WHO. 1998;76:327-33.

28. Courtin F, Carpenter TE, Paskin RD, Chomel BB. Temporal patterns of domestic and wildlife rabies in central Namibia stock-ranching area, 19861996. Prev Vet Med. 2000;43:13-28.

29. Emel K. Time-series analysis. https://datajobs.com/data-science-repo/TimeSeries-Analysis-Guide.pdf. Accessed 10 October 2016.

30. Ecotravelworldwide. Ethiopia weather and climate zones. http://www. nationalparks-worldwide.info/eaf/ethiopia/ethiopia-weather.html. Accessed 18 May 2016.

31. Woods JA. Lumpy skin disease virus. In: Dinter Z, Morein B, editors. Virus infections of ruminants. Amsterdam: Elsevier Science publishers BV; 1990. p. 53-67.

32. Linthicum KJ, Davies FG, Bailly CL, Kairo A. Mosquito species succession in a dambo in an east African forest. Mosq News. 1983;43:464-70.

33. Stewart Ibarra AM, Ryan SJ, Beltrán E, Mejía R, Silva M, Munõz A. Dengue vector dynamics (Aedes aegypti) influenced by climate and social factors in Ecuador: implications for targeted control. PLoS One. 2013;8:11.

34. Radostits OM, Gay CC, Hinchcliff KW, Constable PD. Veterinary medicine: a textbook of the diseases of cattle, sheep, pigs, goats and horses. 10th ed. Spain: Sounders Elsevier; 2007. p. 1424-6.

35. Ayelet G, Abate Y, Sisay T, Nigussie H, Gelaye E, Jemberie S, Asmare K. Lumpy skin disease: preliminary vaccine efficacy assessment and overview on outbreak impact in dairy cattle at Debre Zeit, central Ethiopia. Antivir Res. 2013;98:261-5.

36. Ben-Gera J, Klement E, Khinich E, Stram Y, Shpigel NY. Comparison of the efficacy of Neethling lumpy skin disease virus and x10RM65 sheep-pox live attenuated vaccines for the prevention of lumpy skin disease - the results of a randomized controlled field study. Vaccine. 2015:33:4837-42.

\section{Submit your next manuscript to BioMed Central and we will help you at every step:}

- We accept pre-submission inquiries

- Our selector tool helps you to find the most relevant journal

- We provide round the clock customer support

- Convenient online submission

- Thorough peer review

- Inclusion in PubMed and all major indexing services

- Maximum visibility for your research

Submit your manuscript at www.biomedcentral.com/submit
) Biomed Central 